\title{
Right aortic arch and an aberrant left subclavian artery arising from a Kommerell diverticulum complicated by acute aortic dissection
}

\author{
Joon Bum Kim, MD, ${ }^{a}$ Dong Hyun Yang, MD, ${ }^{\mathrm{b}}$ and Joon-Won Kang, $\mathrm{MD}^{\mathrm{b}}$
}

\begin{abstract}
A 32-year-old man without Marfan syndrome with abrupt onset of back pain was noted to have a right-sided aortic arch with an aberrant left subclavian artery originating from a Kommerell diverticulum, which was complicated by acute aortic dissection (Figure 1). Arch branches arose in the following order: left common carotid artery, right common carotid artery, right subclavian artery, and left subclavian artery. The distal arch and proximal descending aorta were located posterior to the trachea and esophagus
\end{abstract}

From the Departments of Thoracic and Cardiovascular Surgery and Radiology, ${ }^{\mathrm{b}}$ Asan Medical Center, University of Ulsan College of Medicine, Seoul, Republic of Korea.

Disclosures: Authors have nothing to disclose with regard to commercial support. Received for publication June 4, 2012; accepted for publication June 18, 2012; available ahead of print July 26, 2012

Address for reprints: Joon Bum Kim, MD, Department of Thoracic and Cardiovascular Surgery, Asan Medical Center, 88, Olympic-Ro 43-Gil, Songpa-Gu, Seoul, 138-736, Republic of Korea (E-mail: jbkim1975@amc.seoul.kr).

J Thorac Cardiovasc Surg 2012;144:978-9

0022-5223/\$36.00

Crown Copyright (C) 2012 Published by Elsevier Inc. on behalf of The American Association for Thoracic Surgery

http://dx.doi.org/10.1016/j.jtcvs.2012.06.055
(Figure 1). Intimal tear was observed at mid arch, and the dissection flap involved the aorta between the right common carotid artery and the renal artery, including the Kommerell diverticulum and the left subclavian artery (Figure 2). Because the aortic dissection was complicated by left arm malperfusion, the patient underwent emergency total arch replacement through a median sternotomy, with a distal anastomosis performed distal to the Kommerell diverticulum. Postoperative course was complicated by temporary paraparesis.

This rare form of complex arch anomaly is explained by regression of left aortic arch during the embryologic development. This regression may predispose toward aortic aneurysm, dissection, or rupture. ${ }^{1-3}$

\section{References}

1. Edwards JE. Anomalies of the derivatives of the aortic arch system. Med Clin North Am. 1948;32:925-49.

2. Austin EH, Wolfe WG. Aneurysm of aberrant subclavian artery with a review of the literature. J Vasc Surg. 1985;2:571-7.

3. Cinà CS, Althani H, Pasenau J, Abouzahr L. Kommerell's diverticulum and rightsided aortic arch: a cohort study and review of the literature. J Vasc Surg. 2004;39: $131-9$.

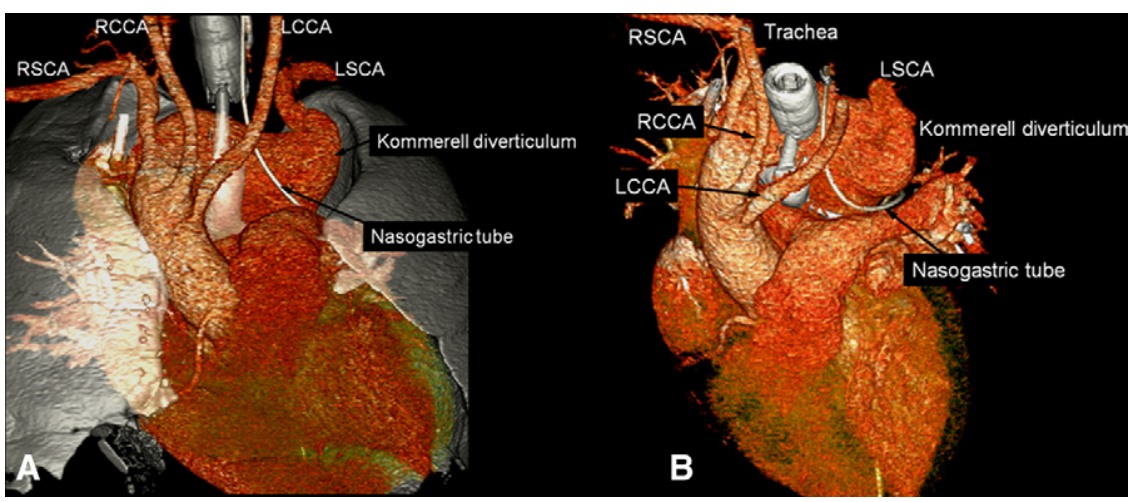

FIGURE 1. Three-dimensional reconstructed computed tomography images of the heart. Right-sided aortic arch with an aberrant left subclavian artery ( $L S C A)$ originating from the Kommerell diverticulum, which was complicated by acute aortic dissection. A, Anteroposterior view. B, Left anterosuperior view. $L C C A$, Left common carotid artery; $R C C A$, right common carotid artery; $R S C A$, right subclavian artery. 


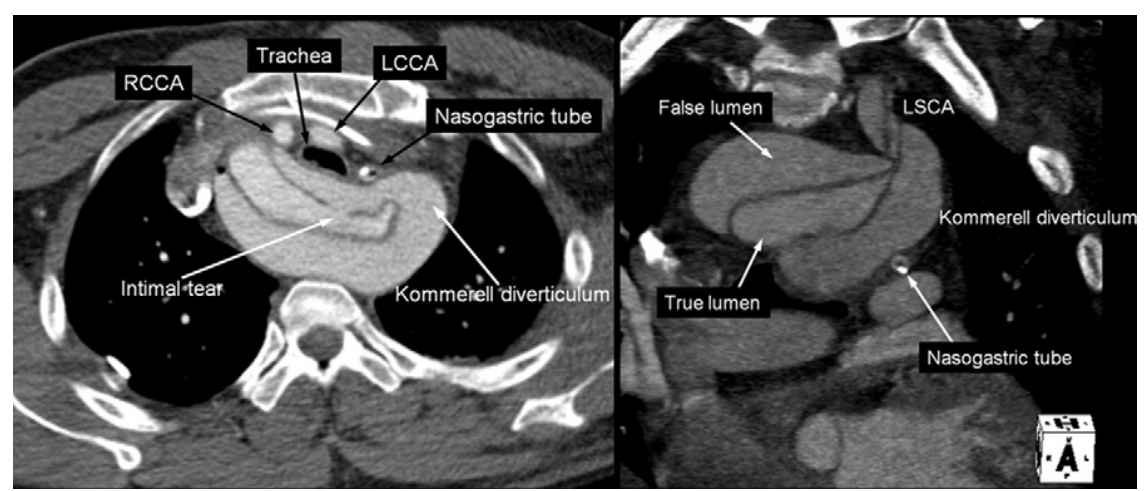

FIGURE 2. Intimal tear at mid arch with dissection flap involving the aorta between the right common carotid artery $(R C C A)$ and the renal artery, including the Kommerell diverticulum and left subclavian artery ( $L S C A)$. LCCA, Left common carotid artery. 